\title{
Hacia nuevos horizontes en el estudio del currículo
}

Towards new horizons in the study of curriculum

Gerardo Roacho Payán ${ }^{1}$

Laura Verónica Herrera Ramos ${ }^{2}$

\section{Resumen}

Este estudio tiene como propósito, un acercamiento crítico al programa Maestría en Educación Media Superior (MEMS, 2014), emanado de la Universidad Pedagógica Nacional del Estado de Chihuahua (UPNECH), Campus Parral; que a la luz de la teoría del currículo y de la formación de profesores, pretende develar la sujeción que la política educativa ejerce sobre los procesos universitarios en la construcción del currículo, reduciendo cada vez más los espacios de crítica y autonomía académica, lo cual impide mantener el enfoque ideológico-político de la universidad en los programas. Convoca al lector a considerar perspectivas curriculares emergentes y afirmar el papel crucial de la universidad en la protección de una educación con valores sociales democráticos. Es una investigación concluida, de enfoque cualitativo y un método hermenéutico crítico que considera los sesgos y limitantes de las fuerzas sociales, económicas y políticas que actúan sobre el investigador (Alvarez y Gayou, 2005) y la hermenéutica profunda de Ricoeur (Thompson, 1993), que emplea métodos tanto interpretativos como explicativos en un círculo hermenéutico, con técnicas de observación, entrevista y análisis de documentos, vistos a la luz de la teoría del currículo.

\section{Palabras clave}

Política educativa, currículo, formación de profesores, crítica, universidad.

1 Gerardo Roacho Payán. Profesor-investigador en la Universidad Pedagógica Nacional del Estado de Chihuahua, Campus Parral, México. Es maestro en psicoterapia. Correo electrónico: groacho@gmail.com

ID: http://orcid.org/0000-0002-7229-5456

2 Laura Verónica Herrera Ramos. Profesora-investigadora en la Universidad Pedagógica Nacional del Estado de Chihuahua, Campus Parral, México. Es doctora en pedagogía crítica. Correo electrónico: veronica19732014@gmail.com

ID: http://orcid.org/0000-0001-8785-0603 
RECIE. Revista Electrónica Científica de Investigación Educativa

Vol. 4, núm. 2, enero-diciembre 2019, pp. 983-993.

\begin{abstract}
The purpose of this study is a critical approach to the master's degree in high school education program (MEMS 2014). Which emerges from the Universidad Pedagógica Naciona del Estado de Chihuahua (UPNECH) campus Parral, that in the light of the theory of the curriculum and the training of professors, it intends to reveal the subjection that the educational policy exerts on the university processes in the construction of the curriculum, reducing more and more the spaces of criticism and academic autonomy, which prevents maintain the ideological-political approach of the university in the programs. It invites the reader to consider emerging curricular perspectives and affirm the crucial role of the university in the protection of an education with democratic social values. It is a concluded research, with a qualitative approach and a critical hermeneutical method that considers the biases and limitations of the social, economic and political forces that act on the researcher (Alvarez and Gayou, 2005) and the deep hermeneutics of Ricoeur (Thompson, 1993) , which uses both interpretive and explanatory methods in a hermeneutic circle, with techniques of observation, interview and analysis of documents, seen in the light of curriculum theory.
\end{abstract}

\title{
Keywords
}

Educational policy, curriculum, teacher training, criticism, university.

\section{Introducción}

La tradición curricular, inicia en un notable fenómeno de inmigración en los Estados Unidos a inicios de la década de 1920, inmerso el país en una etapa industrial, el sector privado se negó a pagar la capacitación de sus empleados convenciendo al sector público de solventar los costos. De esta forma, los migrantes ilegales se convertían en trabajadores americanos contribuyendo a la economía industrial cuya preparación para el trabajo la recibían desde la escuela. (Pinar, 2002), (Traducción propia).

La intrusión de la elite empresarial en la educación no es algo exclusivo de la actual Reforma Integral de la Educación Media Superior (RIEMS, 2008). Los intereses que tiene este grupo se han impuesto como el único referente para dirigir la educación de los jóvenes influyendo enormemente en el presente y el futuro de la sociedad. A través de la OCDE se introduce en México el modelo de educación por competencias, que buscando la calidad de la educación, lo que ha hecho es incrustar a los estudiantes en una lógica mercantil, que utiliza la escuela para formar 
sujetos para la productividad y la competitividad, y en este objetivo los profesores tienen un papel crucial, debido a que la formación docente está sustentada desde las mismas bases.

El fenómeno de la empresa que invade la escuela, se observa en muchos países, y deja ver el rechazo de los profesores a través de la producción de investigación, donde se encuentra un grupo de estudios que develan, que los cambios sociales, políticos e intelectuales; así como las reformas, los títulos, los exámenes, los sueldos, las evaluaciones, y las certificaciones, van tomando un papel central en la formación de profesores, llevándolos a buscar nuevos significados a su profesión. Un segundo grupo, devela los riesgos de la identidad docente, después de que con las reformas educativas los profesores ven el currículo como inalterable; denuncian que los modelos de formación docente de las reformas actuales, ignoran sus necesidades pedagógicas, y condicionan tanto sus procesos formativos y los resultados. Un tercer grupo hace cuestionamientos, ¿Qué es la formación? ¿Cuándo y por qué surge? ¿Cómo debe ser la formación docente? ¿Existe una sola formación o debemos pensarla en plural?; y proponen que los profesores sean parte de los debates y las decisiones en las políticas educativas, que traspasen las fronteras formales de la educación, que cuestionen y comprendan su esencia histórica y política, y participen en la emergencia de una construcción teórica sobre los procesos de formación docente, con una visión dialéctica crítica.

\section{Fundamentación teórica}

Las perspectivas teóricas que se presentan a continuación constituyen los criterios sobre los cuales se valoran el proceso del diseño y las asignaturas del programa de la maestría en cuestión, para dejar ver, que la perspectiva del currículo implica también un determinado diseño y un producto; los académicos que han diseñado el programa no han plasmado su propio eidos (idea), sino que este es externo, modelando un diseño práctico, y asimismo una formación de profesores subyugada.

\section{El interés que orienta la acción}

Aristóteles (Grundy, 1998) examinaba la ética que orienta la acción humana, definía así la poietiké, que en un sentido artístico se refiere a crear, como una escultura o un poema, y en un sentido mecánico, tekné, que se refiere a hacer algo, como construir un puente, por ejemplo. Tanto la poetiké como la tekné se constituyen como habilidades prácticas, pero ambas, son resultado de un eidos (idea). Un profesor puede contar con un amplio conocimiento de su campo docente, pero si su actividad es 
determinada por un eidos externo su ámbito de acción queda limitado. El eidos define la naturaleza del producto, y solo puede concretarse con la tekné. Si la práctica del profesor se define por planes y programas instituidos significa que los educandos son formados por eidos externos que existen desde antes y fuera de su escuela, y los objetivos de aprendizaje que se buscan en el educando, llevan como vehículo la habilidad o tekné del profesor, de este modo la acción docente es separada del eidos, y el profesor solo es el técnico que ejecuta los programas.

\section{El currículo tradicional}

Se remonta a los años veinte del siglo XX, en Denver, cuando el superintendente Newlon, promovió la especialización del currículo, convocando a algunos profesores a dejar las aulas para hacerse cargo de los problemas curriculares desde una oficina (Gimeno y Pérez, 1989). Dos décadas más tarde, Tyler incorpora al currículo tradicional, un método racional basado en la psicología conductual, convirtiéndolo en fuente de autoridad, haciendo de la educación "un proceso de modificación de los patrones de conducta de las personas" (Kemmis, 1993, pág. 26). Luego la ciencia y la revolución orientando la dirección de la educación, por la necesidad de operar la industria con una mano de obra calificada, determinó qué enseñar y cómo. El modelo causó polémica en Stenhouse (1987, cit. en Casarini, 1999 ) por sus metas superficiales y poco significativas, por su antidemocracia al anticipar la conducta, y porque limita al maestro a no poner atención a aspectos no predecibles del estudiante. Distingue cuatro enfoques de formación docente.

El enfoque enciclopedista, el profesor es un especialista que acumula conocimientos, el enfoque comprensivo, donde el profesor prioriza sólo el conocimiento de su disciplina. El de entrenamiento, donde el conocimiento consiste en seguir procedimientos técnicos; y el de adopción de decisiones, el profesor utiliza su razonamiento para definir la intervención práctica en función de los problemas que se presentan, apoyado en la investigación científica (Gimeno y Pérez, 2002).

\section{El currículum práctico}

Ante los principios y métodos agotados tylerianos, y una excesiva confianza en las teorías ajenas a la educación, Schwab declara el campo del currículo en agonía y sostiene, solo se puede dar vida al campo curricular abriéndose a principios y perspectivas críticas emergentes (Gimeno y Pérez, 1989). Los profesores requieren de hacer juicios más allá de esas teorías y resolver los 
problemas escolares con las "artes de la práctica" (Kemmis, 1993, p. 27), con reflexiones y argumentos prudentes, morales y políticos.

La formación de los profesores en la perspectiva práctica, tiene dos enfoques: la formación docente tradicional, que ve en la enseñanza una actividad artesanal sin reflexión, inundada de prejuicios y obstáculos epistemológicos de los profesores; y en el enfoque reflexivo sobre la práctica enfrenta reflexivamente las situaciones complejas, cambiantes, inciertas y conflictivas en la escuela y el aula, pues estas situaciones estas están cargadas de significados y valores, interacciones simbólicas, afectivas, intereses sociales, y escenarios políticos (Gimeno y Pérez, 2002). En este contexto, la primera tarea del profesor será entonces, interpretar el currículo como texto y comprometer en el análisis su propio juicio, rechazando la autoridad y el significado que contiene el currículum técnico, (Grundy, 1998).

\section{El currículum emancipador}

Apple, junto a algunos marxistas y neo-marxistas, después de analizar críticamente el currículo, se identifican con los menos privilegiados y denuncian que la escuela no es neutral, sino que lleva sobre sí una carga de intereses políticos, develan sin tapujos las implicaciones sociales y políticas que actúan sobre la educación con estudios que rompen con los términos de las ciencias sociales tradicionales, posicionándose claramente en los valores de la emancipación política de los individuos; considerando la educación tanto un acto político como intelectual (Gimeno y Pérez, 1989). El currículum emancipador se despliega hacia dos enfoques de formación docente: la Investigación-acción y formación para la comprensión, ve la enseñanza como un arte de expresión concreta y situada, por ello, un profesor no puede considerar la educación como una rutina mecánica, sino un arte donde las ideas se crean de un modo reflexivo para mejorar la calidad de su propia intervención. Y la Crítica y reconstrucción social, que considera que la formación de profesores debe contar con un bagaje cultural de orientación política - social donde desarrollen una capacidad de reflexión que desenmascare la ideología dominante, que analicen los mecanismos de producción e intercambio capitalista (Gimeno y Pérez, 2002), aprender las teorías del poder y opresión, para entender cómo ellos mismos han sido formados y cómo están formando a los educandos (Huerta-Charles y McLaren, 2011). 
RECIE. Revista Electrónica Científica de Investigación Educativa Vol. 4, núm. 2, enero-diciembre 2019, pp. 983-993.

\section{Enfoque metodológico}

Un camino sinuoso en el trabajo del diseño curricular

Una cuestión está sobre la mesa de debate ¿cómo formar a los profesores de educación media superior? Se debe tomar en cuenta que la deserción escolar se incrementa en el bachillerato (SEP, 2012) y los resultados del Programa de Formación de Profesores de Educación Media Superior (PROFORDEMS) que instituye el sistema educativo han sido insatisfactorios. El diagnóstico realizado arrojó a través de una encuesta, que los perfiles docentes en el bachillerato no son afines a la educación, y carecen de conocimientos en áreas de pedagogía, psicología, intervención y didáctica (MEMS, 2014). El campus recibe la propuesta de diseñar la MEMS, un programa que atienda la formación de profesores del bachillerato, bajo la premisa de tener como fondo normativo la Reforma Integral de la Educación Media Superior (RIEMS), un mandato curricular más de posgrado asumido por la universidad, había que incorporar el eidos (Grundy,1998) de la reforma educativa. Por tanto esta, cubría ya con su aparato conceptual el diseño curricular que apenas había de diseñarse.

\section{Organización y estructura curricular}

El trabajo de diseño curricular se proyectó en una metodología constructivista, considera la formación inicial de los profesores, la visión interdisciplinar, las necesidades de los estudiantes, las condiciones de la escuela y las construcciones culturales de los profesores. Considera cuestiones epistemológicas sobre la naturaleza de la socialización del saber, para construir "ideas de cómo puede funcionar la realidad" (Casarini, 1999, pág. 114). Era necesario abordar dos contenidos: las Competencias Docentes y la Construcción de objetos de aprendizaje, por ello estos títulos son los que llevan las dos especialidades que conforman el programa de Maestría en Educación Media Superior.

\section{El sistema modular}

Pansza (2002) caracteriza la estructura modular como una forma de superar la clásica enseñanza por disciplinas, constituida por unidades basadas en la interrogante y el conocimiento de un objeto, conjugando ciencias y técnicas para obtener una respuesta científica, constituyendo de este modo nuevos conocimientos. Con la integración de contenidos, se busca que los profesores lleguen a las cuestiones metodológicas de su quehacer profesional, y puedan llevar a sus propias disciplinas la teoría y práctica pedagógica. A este sistema, Casarini (1999) lo llama "currícula 
abierta" (pág. 126), no para lograr una conducta terminal, sino para desequilibrar las estructuras cognitivas; y para ello, requiere del conocimiento de las disciplinas, de la interdisciplinariedad, la transdisciplinariedad, la toma de decisiones, juicios éticos, de comprensión de los procesos de cada persona individual, de didáctica y compromiso.

Figura 1. Mapa curricular MEMS.

\begin{tabular}{|c|c|c|c|c|c|}
\hline Especialización & $\begin{array}{l}\text { Cuatri } \\
\text { mestr }\end{array}$ & Módulo & \multicolumn{3}{|c|}{ Unidad modular } \\
\hline \multirow{3}{*}{$\begin{array}{c}\text { Formación en } \\
\text { competencias } \\
\text { para la docencia }\end{array}$} & 1 & $\begin{array}{c}\text { Reconocimiento } \\
\text { de la Práctica }\end{array}$ & $\begin{array}{l}\text { Reconocimiento del } \\
\text { Quehacer Docente }\end{array}$ & $\begin{array}{l}\text { Conocimiento del } \\
\text { Adolescente }\end{array}$ & Política Educativa \\
\hline & 2 & $\begin{array}{c}\text { Elaboración del } \\
\text { Diagnóstico }\end{array}$ & $\begin{array}{l}\text { Diagnóstico en el } \\
\text { contexto } \\
\text { sociocultural }\end{array}$ & $\begin{array}{l}\text { Mediación } \\
\text { pedagógica }\end{array}$ & $\begin{array}{c}\text { La REIMS y el } \\
\text { proceso educativo }\end{array}$ \\
\hline & 3 & $\begin{array}{l}\text { Propuesta de } \\
\text { Intervención }\end{array}$ & La Intervención & La Estrategia & Evaluación \\
\hline \multirow{3}{*}{$\begin{array}{c}\text { Formación en } \\
\text { competencias para la } \\
\text { construcción de } \\
\text { objetos de } \\
\text { aprendizaje. }\end{array}$} & 4 & $\begin{array}{l}\text { Aplicación de la } \\
\text { Intervención }\end{array}$ & $\begin{array}{l}\text { Aplicación de la } \\
\text { Intervención }\end{array}$ & $\begin{array}{l}\text { Seguimiento de la } \\
\text { Intervención }\end{array}$ & $\begin{array}{c}\text { Procesos } \\
\text { Interactivos }\end{array}$ \\
\hline & 5 & $\begin{array}{c}\text { Sistematización } \\
\text { de la } \\
\text { Intervención I }\end{array}$ & $\begin{array}{l}\text { Organización de la } \\
\text { información }\end{array}$ & $\begin{array}{l}\text { Estrategias de } \\
\text { intervención }\end{array}$ & $\begin{array}{c}\text { Campos de } \\
\text { intervención I }\end{array}$ \\
\hline & 6 & $\begin{array}{c}\text { Sistematización } \\
\text { de la } \\
\text { Intervención II }\end{array}$ & $\begin{array}{l}\text { Elaboración del } \\
\text { Informe }\end{array}$ & $\begin{array}{l}\text { Desarrollo del } \\
\text { aparato crítico }\end{array}$ & $\begin{array}{c}\text { Campos de } \\
\text { intervención II }\end{array}$ \\
\hline
\end{tabular}

\section{Resultados}

Después de presentar las perspectivas curriculares técnica, práctica y emancipadora, así como sus implicaciones en el papel del profesor en la educación, se afirma que el diseño curricular de la MEMS contiene elementos tanto técnicos como prácticos, que de forma aislada, no le permiten llegar a la praxis, y se describen a continuación.

El programa de la MEMS pertenece a un enfoque tradicionalista, que pretende solucionar los problemas escolares desde una oficina (Gimeno y Pérez, 1989); del mismo modo, los académicos de la UPNECH han diseñado un currículo para dar respuesta a los problemas de los profesores de la media superior. El eidos de la MEMS es de un agente externo, el eidos empresarial con sus conceptos, su lenguaje, sus propósitos, sus contenidos, su estructura y su visión del mundo, "calidad", "eficiencia", "estándares" y 
“competencias" (RIEMS, 2008). Los académicos de UPNECH, aportan solo su habilidad (tekné) para diseñar el currículo, no participan del eidos, han sido solo una parte del proceso, que convierte al programa en una tecnología empresarial para formar a los profesores, proveyendo más utilidad al estado moderno mercantil que a los códigos y valores sociales.

La política educativa de la RIEMS (2008) se instituyó como fundamento político y normativo en el diseño, en una asignatura del módulo I: Política Educativa; y en el módulo II: La RIEMS y el Proceso Educativo, (UPNECH, 2014, p. 52 y 54); y aunque ambos constituyeron el blanco de la crítica para la construcción del diseño, debido al eidos que lo cubre, no permitió un rumbo crítico para una praxis, haciendo de la escuela un engrane más del sistema de producción capitalista.

El curso Conocimiento del adolescente (UPNECH, 2014, p. 52), brinda conocimientos para dar nuevos significados a los adolescentes en un acercamiento a aspectos sociales, emocionales y cognitivos, y poder verlos como sujetos que no solo van a la escuela a aprender, sino también su condición humana y social.

El curso de Procesos interactivos (UPNECH, 2014, pág. 60), los profesores ponen en juego su ética en una situación humana educativa, por encima de lo convencional, a "cómo deben hacerse las cosas, y no a qué cosas deben hacerse" (Kemmis, 1993, pág. 6), el campo de esta interacción humana es una forma de acción asociada al interés práctico (Grundy, 1998), para plantear situaciones y ambientes de clase que den oportunidades y mejores condiciones para aprender.

No obstante, el enfoque práctico de la MEMS deja la educación como algo independiente de la realidad social en que está inmersa, con sesgos que no ven la totalidad, ni el trasfondo económico y político (Gimeno y Pérez, 1989), la MEMS contribuye a conservar el orden social, transforma la realidad inmediata, pero no considera las implicaciones sociales y económicas del todo. La teoría y la práctica de la MEMS quedan en una relación lineal que no trasciende sus propios límites, con el planteamiento de una intervención educativa concreta y situada en lo práctico, lejos de la praxis.

La posibilidad de fomentar un pensamiento crítico dentro del currículo de la MEMS es apenas un atisbo en los cursos de "Política educativa" (UPNECH, 2014, pág. 51) y "La RIEMS en el proceso educativo" (pág. 54), con elementos que con la deliberación del profesor puede llevar a los profesores a reflexionar la carga de intereses políticos que posee la reforma al bachillerato; pero a la vez, carece de una teoría epistemológica, 
política y sociológica que dé lugar al des-ocultamiento de los intereses de poder que se disputan en la escuela y las relaciones sociales verticales de explotación, opresión y de desigualdad que ahí se reproducen (Martínez, 2011). El currículo emancipatorio, busca formar profesores para que adquieran un bagaje cultural de orientación política y social que desarrolle su capacidad de reflexión crítica para desenmascarar la ideología dominante y transformar la escuela.

Asimismo en el curso Mediación Pedagógica se cuestionan las distintas visiones de la educación en los modelos tradicional, escuela nueva y pedagogía crítica, sin embargo el material teórico se observa apenas incipiente para dejar claro que los problemas de la escuela no se pueden resolver con simples instrucciones, requiriendo un sustento más sólido para develar las implicaciones políticas que actúan sobre la educación, y además, entender que para que haya cambios, es necesario cambiar la estructura de la cultura (Gimeno y Pérez, 1989).

Por otra parte, los profesores de Educación Media Superior a quienes se dirige este programa, solo participaron al contestar una encuesta que reflejó resultados cuantitativos, no fueron parte de la creación de la MEMS, su papel fue pasivo y receptor. "en un carácter dialógico (...), se trata de un currículo negociado (...) un concepto de colaboración de praxis curricular" (Grundy, 1998, p. 189), para llegar a la praxis, requiere del desarrollo de una conciencia crítica dentro del "seno de la comunidad educativa" (Apple, 1970, cit. en Grundy, 1998, p. 171),

\section{Conclusiones}

En la MEMS, se sobrevaloraron las cuestiones metodológicas en detrimento de las cuestiones epistemológicas. El programa no provee de teorías epistemológicas, del origen de las ideas, de las ciencias, o de los paradigmas que le dieran fondo sólido a sus reflexiones.

Los diseñadores de la MEMS, pensaban su trabajo académico dentro de las posibilidades de un pensamiento crítico dado el espíritu de la universidad, su historia y su orientación política; sin embargo, se puede ver que la política educativa permea los procesos académicos, debilitando cada vez más la libre acción en el campo del currrículo.

Mientras que la Universidad Pedagógica Nacional se consideraba por los propios profesores, sitio para el desarrollo, la discusión y el debate de las teorías educativas de vanguardia y matriz de programas de estudio para la formación y profesionalización de los profesores; hoy, a raíz de que la universidad ha sido tomada como instrumento por el Estado y los intereses económicos, el beneficio se redirige no para el público, sino para la clase en 
el poder y el estado moderno empresarial, caracterizado por la proyección global de su discurso, de que los resultados y el incremento de la productividad, ha triunfado sobre la escuela (Pinar, 2002). Pero ¿Cómo propiciar un diálogo democrático en el estudio del currículo?

Pinar (2002) es insistente al afirmar que debemos conocer una serie de estudios no norteamericanos que ameriten un debate vigoroso, que nos ayuden a entender el currículo en una visión horizontal del campo (entre regiones de todo el mundo), compatible con la visión vertical (de lo global a lo local) de estudios históricos, prospectivos y de localidad que marchan al unísono y dan cuenta de los problemas de la educación y que podrían llevarnos a la descolonización comprometida ética y políticamente desde "el no lugar del imperio" (Hardt y Negry, 2000, cit. en Pinar, 2002, p. 25) donde "el nacionalismo y la nación se postula como el sitio de la resistencia contra la dominación del capital extranjero y / o global", "con el fin de reorientar y reanimar luchas de resistencia al racismo, el clasismo y la misoginia" (Pinar, 2002, p. 23).

\section{Referencias}

Alvarez J. Y Gayou, J. (2005). Cómo hacer investigación cualitativa. Fundamentos y metodología, México: Paidós.

Casarini, R. M. (1999). Teoría y diseño curricular. México: Trillas

DOF (2008). Diario Oficial de la Federación. Tercera sección. Acuerdo número 447 por el que se establecen las competencias docentes para quienes impartan educación media superior en la modalidad escolarizada.

Gimeno, S. Y Pérez G. (1989). La enseñanza, la teoría y su práctica. 3aㅗ edición. España: Akal.

Gimeno, S. Y Pérez G. (2002). Comprender y transformar la enseñanza. Décima Edición. Ediciones Morata, S.L.

Grundy, S. (1998). Producto o praxis del currículo. Madrid: Morata.

Kemmis, S. (1993). El currículum: Más allá de una teoría de la reproducción. Ed. Morata. Segunda edición. Madrid.

Martínez, R. (2011). Teoría crítica e investigación educativa. Imaginarios políticos de una definición polémica. Instituto de Pedagogía CríticaDoble Hélice Ediciones, col. Cuadernos de pedagogía crítica. núm. 3. Chihuahua. México.

McLaren, P. y Huerta-Charles, L. (2011). Educación pública y formación de profesores: una visión desde la pedagogía crítica revolucionaria 
Innovación Educativa, vol. 11, núm. 57, octubre-diciembre. Instituto Politécnico Nacional. México.

Núñez R. N. (2008). El currículo modular ¿exigencia o alternativa? Extraído desde http://articulosusat.blogspot.com

OCDE (2010). Acuerdo de cooperación México-OCDE para mejorar la calidad de la educación de las escuelas mexicanas. Mejorar las escuelas: Estrategias para la acción en México Establecimiento de un marco para la evaluación e incentivos para docentes: Consideraciones para México Resúmenes ejecutivos. extraído desde https://www.oecd.org.

Pansza, M. (2002). Pedagogía y currículo. Mèxico: Gernika.

Pinar, W. (2002). The internationalization of Curriculum Studies: a status report. New Orleans, 2002. (Mimeo).

RIEMS (2008). Reforma Educativa de la Educación Media Superior. extraída desde http://www.sems.gob.mx

SEP (2012). Estadísticas Básicas del Sistema Educativo Nacional. Educación Media Superior. Disponible en https://www.gob.mx

Thompson, J. (1993). Ideología y cultura moderna. Teoría crítica social en la era de la comunicación de masas. México: UAM.

UPNECH (2014). Programa de Maestría en Educación Media Superior. Secretaria de Educación, Cultura y Deporte Del Estado De Chihuahua. Universidad Pedagógica Nacional del Estado de Chihuahua. 
RECIE. Revista Electrónica Científica de Investigación Educativa Vol. 4, núm. 2, enero-diciembre 2019, pp. 983-993. 